\title{
An Empirical Study of Social Support among Depressive and Non- Depressive Elderly People
}

\author{
Satvinder Singh Saini ${ }^{1 *}$
}

\section{ABSTRACT}

It has been documented that elderly are more prone to psychological problems and depression is the commonest geriatric psychiatric disorders. In fact the elderly in India face a multitude of psychological, social and physical health problems. In a cross-sectional study, it was found that in persons 65 years and older, the perceived adequacy of emotional and tangible support was clearly associated with depressive symptoms. Aim and Objective: This study intends to see the relationship between depression and social support among depressive and non-depressive elderly. Samples and Methods: This study comprised of 60 (30 with depression and 30 without depression) participants of age 60 or above. The sample was selected with purposive incidental sampling technique. Material used: GDS-30 and PGI- SSQ were administered after taking consent. Results and conclusion: Result shows the comparison of means between depressive (case-group) and non-depressive (control-group) as per the scores on Social Support Questionnaire (SSQ). The mean score (40.53) of depressive group was lesser than that of nondepressive group (50.30). The t-value (20.373) was found to be statistically significant at 0.01 . (p-value 0.000). Conclusion: In brief, the findings of the study show that depressed people perceive lack of social support than non-depressed elderly people. It has been observed that social support is a protective factor from depression in elderly people.

Keywords: Depression, Social Support, Depressive and Non-depressive elderly

Ageing is a universal process associated with deteriorating health status. With the passage of time certain changes take place in an organism leading to morbidities, disabilities and even death. With a rapidly aging society, geriatric mental health is emerging as an important public health concern. Depression is a frequent cause of distress in older adults; leading to physical, mental, and social dysfunction; and often decreasing quality of life.

The latest World Health Assembly of 24 May 2013 considered older people to be a vulnerable group, with a high risk of experiencing mental health problems and the number of older adults is

\footnotetext{
${ }^{1}$ Clinical Psychologist, Yamunanagar, Haryana, India

*Responding Author

(C) 2016 Singh S; licensee IJIP. This is an Open Access Research distributed under the terms of the Creative Commons Attribution License (http://creativecommons.org/licenses/by/2.0), which permits unrestricted use, distribution, and reproduction in any Medium, provided the original work is properly cited.
} 


\section{An Empirical Study of Social Support among Depressive and Non-Depressive Elderly People}

growing fast all over the world. The socioeconomic impact of such demographic changes is adding to the overall mental health consequences. (WHO, 2013)

Depression is recognized as a serious public health concern in developing countries. The Global Burden of Disease study showed that depression will be the single leading cause of Disability Adjusted Life Years by 2020 in the developing world. (Murray \& Lopez, 1997) Depression is the most common psychiatric disorder among the elderly which can manifest as major depression or as minor depression characterized by a collection of mild depressive symptoms (Satcher, 2000)

Prevalence of depression in elderly in India has varied from 6\% to $50 \%$ in different studies (Venkoba, 1993 \& Nandi et al.1997). Important risk factors in late life depression are loss of partner, low socio-economic status (low level of income and education), low social and interpersonal support (small network size, low exchange of instrumental and emotional support), certain personality characteristics (neuroticism, more external locus of control) and impaired cognitive functioning (Vink \& Aartsen et al., 2008).

Social support is often used in a broad sense, referring to any process through which social relations might promote health and well-being; it refers to the social resources that persons perceive to be available or that are actually provided to them by non-professionals in the context of both formal support groups and informal helping relations (Cohen, Gottlied \& Undewood, 2000)

Social support is a concept that is generally understood by intuitive sense, as the help from other people in a difficult life situation. One of the first definitions put forward by Cobb (1976), defined social support as the individual belief that one is cared for and loved, esteemed and valued, and belongs to a network of communication and mutual obligations. This concept is strategic in understanding the maintenance of health and the development of mental and somatic health problems, as well as their prevention. Types and sources of social support can vary. Four main categories of social support have been identified: emotional, appraisal, informational and instrumental support (Cobb, 1976). Social support is closely related to the concept of social network, the ties to family, friends, neighbours, and other significant persons. Within the concept of social network, social support is the potential of the network to provide help. Social support has two separate domains, structural and functional (Cobb 1976). Structural social support is the actual physicality of the support such as frequency of contact with friends or family, voluntary organizations or associations, religious services and other community service. Functional social support includes happiness with such areas as verbal and physical appraisal, tangible help with tasks, communication of helpful information and guidance and social companionship (Cobb 1976; Cutrona 1990). 


\section{An Empirical Study of Social Support among Depressive and Non-Depressive Elderly People}

Social support theory suggests that structural social support is a necessary antecedent of functional support (Queenan, Feldman-Stewart, Brundage, Groome 2010). Evidence suggests, however, that the perception of social support (functional) is more predictive of positive health than received or available social support (Cohen, Doyle, Turner, Alper \& Skoner 2003; Sherebourne \& Stewart 1991). For decades researchers have been fascinated by the complexity of social networks and systems of social support. There is now a wealth of research on the importance of social interaction for quality of life during old age. This diverse body of literature has been summarized and organized into three areas, each with a different focus (Chappell. 1992). There has been vast and frequently inconsistent literature on the importance of social support in the lives of elderly people, but less research on the form of support that is best. Social support is an important factor that may buffer the ill effects of stress on mental and physical health. In a cross-sectional study of 707 older adults, it was found that a positive association existed between social support and recovery from depression (Hay, Steffens, Flint Bosworth \& George 2001). Social support has been shown to moderate the effects of health related strain on mental health in 410 elderly individuals (Hagerty \& Williams 1999). Lack of social support affects the overall health of an individual. According to Rook (1985), absence of social support has been linked to decline in cognitive function. Social support, social exchange and social network are related constructs, which may be powerful and potentially modifiable determinants of cognitive health and mortality in the elderly population (Jordan-Marsh \& Harden 2005). Absence or disruption of contact with significant others, which frequently occurs when one ages or is ill, has been linked to a number of physical and mental health indices including increased mortality after myocardial infarction (Berkman, et al. ,1992). These same researchers found that those with little social support were at increased risk of institutionalization.

In a cross-sectional study by George Blazer, Hughes and Fowler (1989), a decrease in social support over a one-year interval was found to be associated with increased psychiatric symptoms, including depression, in a sample of old people. Furthermore, it was found that quality, not quantity, of the support was the most important factor. This makes it clearly important to further investigate the effect of quality of each type of social network in the elderly. In a study by Adams and colleague (2004), receiving fewer visits from friends, and having less extensive social network predicted loneliness. Mac-Arthur studies on successful aging have validated the linkage of social relationship to longevity (Rowe \& Kahn 2002)

Some experts suggest that social support provides a sense of connectedness to one's social group, which results in feelings of well being (Ryan. 1995). More social support was related to positive cognitive functioning in old people and that quality, not quantity, of support was the most important factor (Ryan). Furthermore, disruptions in the makeup of social network such as change of residence or death of close friends or family members, may lead to increased loneliness in this age group, especially when it has been found that older adults form new social connections less easily than younger persons. This may be a problem for those in age-segregated 


\section{An Empirical Study of Social Support among Depressive and Non-Depressive Elderly People}

communities where individuals have left their traditional neighborhoods in order to obtain services and amenities. Social support, defined as both structural characteristics of a social network and perceived availability of resources, has been proposed to affect the onset, course and outcome of depression (Billings \& Moos, 1984; Conyne \& Downey 1991). It has been hypothesized that this occurs as a direct effect or as a buffering effect during stress conditions (Dooley, 1985). In summary, a lack of social relationship has been found to be related to loneliness, and loneliness can lead to a serious mental condition of depression.

\section{Objectives:}

1. To assess the level of depression and social support among elderly with and without depression

2. To compare the level of social support between depressive and non-depressive elderly people

3. To test the co-relation between depression and social support

\section{Hypothesis:}

Keeping in view the aforementioned objective, the following hypotheses were framed:

1. There would be significant difference in scores of social support between depressive and non-depressive elderly people

2. There would be negative correlation between social support and depression

\section{RESEARCH METHODOLOGY}

Research Design:

This study was cross-sectional and comparative in nature. Face-to-face interview survey method using structured questionnaires was adopted for this study.

\section{Sample:}

An incidental purposive sample of 60 subjects (30 with diagnosis of depression and 30 without depression) aged 60 years or above fulfilling the inclusion criteria were selected for the study.

\section{Inclusion criteria for case group:}

- $\quad$ Patient aged 60 years or above (Any gender) with diagnosis of depression as per ICD-10 DCR ( Non-psychotic Features)

- $\quad$ Able to read and write English/Hindi/Punjabi

- $\quad$ Score $\geq 10$ on Geriatric depression Scale

- $\quad$ Patient who gave consent for participation in study

\section{Exclusion criteria for case group:}

- $\quad$ Patient who had co-morbid substance abuse, intellectual disability or any other psychiatric disorder 


\section{An Empirical Study of Social Support among Depressive and Non-Depressive Elderly People}

- $\quad$ Patient with definitive diagnosis of dementia or non-depressive psychiatric illness, which may preclude accurate screening for depression

\section{Inclusion Criteria For Control Group:}

- $\quad$ Patient aged 60 years or above (Any gender)

- $\quad$ Geriatric Depression Score $<9$

- $\quad$ One who could read /write Hindi/English/Punjabi

- $\quad$ Patient who gave consent for participation in study

\section{Exclusion Criteria For Control Group:}

- Patient who had co-morbid substance abuse, intellectual disability and any other psychiatric disorder

- Patient with definitive diagnosis of dementia

\section{Material Used:}

\section{Geriatric Depression Scale-Hindi Version (GDS-H)}

The Geriatric Depression Scale (GDS) was created in 1983 by Yesavage et al. The instrument has been tested and used extensively with the older population in many countries and translated into many languages. The target population for the GDS is healthy or medically ill and mild to moderately cognitively impaired older adults. It has been used in research among older adults in community, acute and long-term care settings. Hindi version of GDS is prepared by Ganguli et al. in 1999. It is found to have $92 \%$ sensitivity and $89 \%$ specificity.

\section{Social support Questionnaire}

PGI Social Support Questionnaire (PGI.-SSQ) is developed by Nehra et al. in 1998 to measure social support available to the individual. It is an 18 item (in Hindi) scale with the reliability $\mathrm{r}=.59(\mathrm{p}<.01)$ and validity $.80(\mathrm{p}<.01)$, each item differentiates normal people from neurotics at.01 level.

\section{Procedure:}

30 elderly participants with diagnosis of depression (Age $=60$ or above) were recruited in case group for the study from OPD services of Department of Psychiatry of a Govt. Hospital in Chandigarh and 30 non-depressive geriatric subjects were recruited from the registration counter of the same Hospital. An informed written consent for the study was taken from the patients meeting inclusion criteria. Thereafter Socio-demographic details were recorded and GDS and PGI-SSQ Scales were administered. No interference was done by the investigator in treatment and no advice was provided regarding the treatment. These cases were referred back to respective consultant after data collection. Data collected from the assessment were analyzed using relevant statistical methods. The assessment procedure with each individual took about 1 hour. 
An Empirical Study of Social Support among Depressive and Non-Depressive Elderly People

RESULTS AND DISCUSSION

Table -1: Mean and Standard Deviation of age of depressive and non-depressive groups

\begin{tabular}{|l|l|l|l|l|}
\hline \multirow{4}{*}{ Age } & Group & N & Mean & $\begin{array}{l}\text { Standard } \\
\text { Deviation }\end{array}$ \\
\cline { 2 - 5 } & Depression & 30 & 65.57 & 4.94 \\
\cline { 2 - 5 } & Non-depression & 30 & 65.70 & 5.49 \\
\hline
\end{tabular}

Table- 1 shows the mean age of depressive group i.e. case group, was 65.57 years with standard deviation of 4.94. In non-depressive i.e. control group, the mean age was 65.70 year with standard deviation of 5.49. Both the groups had similar mean age around 65 years.

Table-2: Socio-demographic characteristics of Depressive and Non-depressive groups

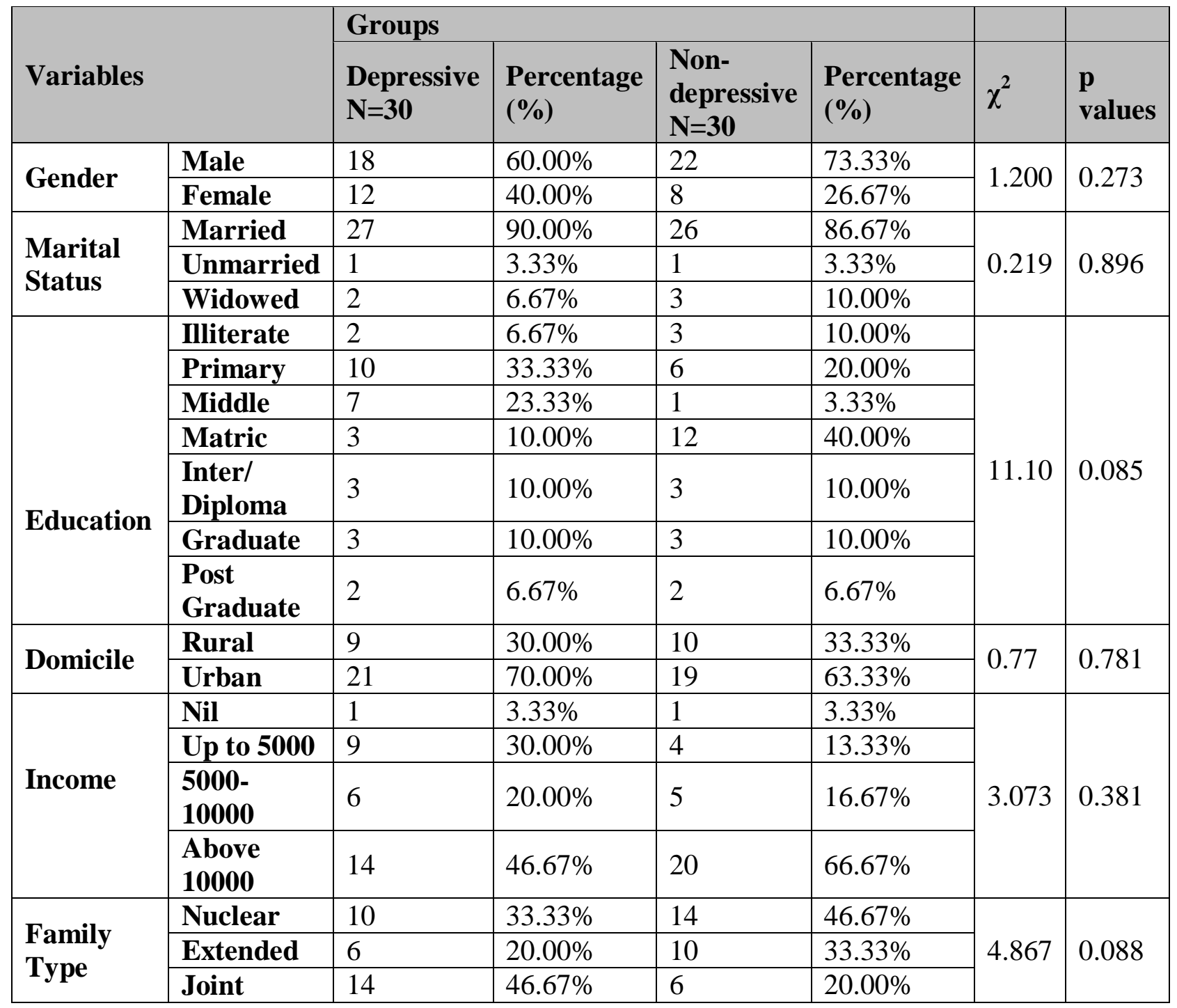

.** Significant at 0.01 (2 tailed) * Significant at 0.05 (2 tailed)

(c) The International Journal of Indian Psychology, ISSN 2348-5396 (e)| ISSN: 2349-3429 (p) | 136 


\section{An Empirical Study of Social Support among Depressive and Non-Depressive Elderly People}

Table-2 shows that out of 60 subjects, majority were males. In case group and control group, $60 \%$ and $73.33 \%$ respectively were males. In case group, most of the subjects (90\%) were married. In control group too majority of the subjects (86\%) were married. Majority (33.33\%) of the subjects were educated up to primary in depression group whereas most of the subjects (40\%) of non-depressive group were educated up to matriculation. Majority of the subjects in both groups were urban. In case group $70 \%$ and in control group $63.33 \%$ were urban. In case group majority of subject (46.67\%) had income above 10,000. In control group (66.67\%) subjects had income above 10,000. In case group most of the subjects (46.67\%) were living in joint families whereas in control group majority (46.67\%) was from nuclear families.

As shown in table-2, on each socio-demographic variable the chi-square value was found to be statistically non-significant, so both groups were comparable on all socio-demographic variables.

Table-3: Mean, Standard Deviation, and t-value of Geriatric Depression Scale (GDS) scores of Depressive and Non-Depressive groups

\begin{tabular}{|l|l|l|l|l|l|l|l|}
\hline Variable & Group & $\mathbf{N}$ & Mean & $\begin{array}{l}\text { Standard } \\
\text { Deviation }\end{array}$ & $\begin{array}{l}\text { Standard } \\
\text { Error } \\
\text { Mean }\end{array}$ & t-value & p-value \\
\hline \multirow{2}{*}{ GDS } & Depressive & 30 & 23.33 & 4.18 & 0.76 & \multirow{2}{*}{20.373} & $0.000^{* *}$ \\
\cline { 2 - 8 } & $\begin{array}{l}\text { Non- } \\
\text { depressive }\end{array}$ & 30 & 5.53 & 2.33 & 0.42 & \\
\hline
\end{tabular}

** Significant at 0.01 (2 tailed) * Significant at 0.05 (2 tailed)

Table-3 shows the comparison of means between depressive (case-group) and non-depressive (control-group) as per the scores on Geriatric Depression Scale (GDS) .The mean score (23.33) of depressive group was higher than that of non-depressive group (5.53). The t-value (20.373) was found to be statistically significant at 0.01 . (p-value 0.000 ).

Table-4: Mean, Standard Deviation, and t-value of Social Support Questionnaire (SSQ) scores of Depressive and Non-Depressive Groups

\begin{tabular}{|c|c|c|c|c|c|c|c|}
\hline Variable & Group & $\mathbf{N}$ & Mean & $\begin{array}{l}\text { Standard } \\
\text { Deviation }\end{array}$ & $\begin{array}{l}\text { Standard } \\
\text { Error } \\
\text { Mean }\end{array}$ & t-value & p-value \\
\hline \multirow[b]{2}{*}{ SSQ } & Depressive & 30 & 40.53 & 7.20 & 1.31 & \multirow[b]{2}{*}{5.650} & \multirow[b]{2}{*}{$0.000 * *$} \\
\hline & $\begin{array}{l}\text { Non- } \\
\text { depressive }\end{array}$ & 30 & 50.30 & 6.14 & 1.12 & & \\
\hline
\end{tabular}

** Significant at 0.01 (2 tailed) * Significant at 0.05 (2 tailed)

Table-4 shows the comparison of means between depressive (case-group) and non-depressive (control-group) as per the scores on Social Support Questionnaire (SSQ).The mean score 


\section{An Empirical Study of Social Support among Depressive and Non-Depressive Elderly People}

(40.53) of depressive group was lesser than that of non-depressive group (50.30). The t-value (5.650) was found to be statistically significant at 0.01 . (p-value 0.000 ).

Table-5: Correlation among variables of the study

\begin{tabular}{|l|l|l|}
\hline Variables & GDS & SSQ \\
\hline GDS & 1 & $-.644^{* *}$ \\
\hline SSQ & $-.644^{* *}$ & 1 \\
\hline
\end{tabular}

Table: 5 shows that there is negative correlation $(r=-.644)$ between the GDS and SSQ score which is significant at 0.01 level

Findings of the present study are also supported by a cross-sectional study conducted by George et al. in 1989, in which, a decrease in social support over a one-year interval was found to be associated with increased psychiatric symptoms, including depression, in a sample of old people.

\section{CONCLUSION}

In brief, the findings of the study show that depressed people perceive lack of social support than non-depressed elderly people. It has been observed that social support is a protective factor from depression in elderly people. Thus both the hypotheses were approved by this study

\section{LIMITATIONS OF THE STUDY}

1. Social support is measured in different ways. This is commonly found in social science research and may lead to a variety of differing conclusions.

2. Specific regional characteristics of the population under study may lead to restrictions in external validity.

3. Numerous demographic, social support and health variables were not included which might have an effect on depression among the aged.

4. The study has a small sample size and may not be a representative of older general population.

\section{Acknowledgments}

The author appreciates all those who participated in the study and helped to facilitate the research process.

\section{Conflict of Interests}

The author declared no conflict of interests. 


\section{An Empirical Study of Social Support among Depressive and Non-Depressive Elderly People}

\section{REFERENCES}

Adams, K. B., Sanders, S., \& Auth, E. A. (2004) . Loneliness and depression in independently living retirement communities: Risk and resilience factors. Journal of Aging and Mental Health, 8, 475-485.

Berkman, L., Leo-Summers, L., \& Horowitz, R. (1992). Emotional support and survival after myocardial infarction: A prospective, population-based study of the elderly.Annals of Internal Medicine, 117, 1003-1009.

Billings, A. G., Moos, R. H. (1984). Coping, stress and social resources among adults with unipolar depression. J Pers Soc Psychol , 46, 877-91.

Chappel, L.N. (1992) Social support and aging. Butterworths perspectives on individual and population aging services. Butterworth Toronto and Vancouver.

Cobb, S. (1976). Social support as a moderator of life stress. Psychometric Medicine, 38,300314.

Cohen S., Gottlieb B., Underwood L.G. (2000). Social Support Measurement and inervention. New York: Oxford University Press

Cohen, S., Doyle, W. J., Turner, R. B., Alper, C. M., \& Skoner, D. P. (2003). Sociability and susceptibility to the common cold. Psychological Science, 14, 389-395

Coyne, J.C., \& Downey, G. (1991). Social factors in psychopathology: Stress, social support, and coping processes. Annual Review of Psychology, 43, 401-425.

Cutrona, C. E. (1990). Stress and social support - In search of optimal matching. Journal of Social and Clinical Psychology, 9, 3-14.

Dooley, D. (1985). Causal inference in the study of social support. In S. Cohen \& S.L. Syme (Eds.), Social support and health Orlando: Academic Press. (pp. 109-125).

Ganguli M., Dube S., Johnston J.M., Pandav R, Chandra V Dodge H.H. (1999) Depressive symptoms, cognitive impairment and functional impairment in a rural elderly population in India: A Hindi version of geriatric depression scale. International Journal of Geriatric Psychiatry,14, 807-20.

George, L. K., Blazer, D.G., Hughes, D. C., \& Fowler, N. (1989). Social support and the outcome of major depression. British Journal of Psychiatry, 154, 478-485.

Hagerty, B. M., \& Williams, A. R. (1999).The effects of sense of belonging, social support, conflict, and loneliness on depression. Lippincott Williams \& Wilkins, Inc, 48, 215-219.

Hay, J. C., Steffens, D. C., Flint, E. P., Bosworth, H. B., \& George, L. K. (2001). Does social support buffer functional decline in the elderly patients with uni-polar depression. American Journal of Psychiatry, 158, 1850-1855.

Jordan-Marsh, M., \& Harden, T. H. (2005). Fictive Kin: Friends as family supporting older adults as they age. Journal of Gerontological Nursing, 31,24-31.

Lebowitz, B.D., Pearson, J.L., Schneider, L.S., Reynolds C.F. , Alexopoulos GS, Bruce ML, et al.(1997). Diagnosis and treatment of depression in late life. Consensus statement update. JAMA, 278, 1186-90. 


\section{An Empirical Study of Social Support among Depressive and Non-Depressive Elderly People}

Murray C.J.L. \& Lopez A.D. (1997). Alternative projections of mortality and disability by cause 1990-2020: Global Burden of Disease Study. Lancet, 349,1498-504.

Nandi P.S., Banerjee G., Mukherjee S.P., Nandi S, Nandi D.N.(1997). A study of psychiatric morbidity of the elderly population in a rural community in West Bengal. Indian Journal of Psychiatry. 39:12.

Nehra R., Kulhara P, Verma S.K. (1998). Manual for P.G.I. social support questionnaire, Varanasi: India Rupa Psychological Centre.

Queenan, J. A., Feldman-Stewart, D., Brundage., Groome, P. A. (2010). Social support and quality of life of prostate cancer patients after radiotherapy treatment. European Journal of Cancer Care, 19, 251-259.

Rook, K. S. (1985). The functions of social bonds: Perspectives from research on social support, loneliness, and social isolation. In I.G. Sarason \& B.R. Sarason (Eds), Social support: Theory, research and applications (pp243-268). Boston: Martinus Nijhoff.

Rowe \& Kahn. (2002). Model of Successful Aging Revisited: Positive Spirituality- The Forgotten Factor The Gerontologist 42, 613-620

Ryan, C. M. ( 1995). Loneliness, social support and depression as interactive variables with cognitive status: Testing Roy’s model. Nursing Sciences Quarterly, 9, 107- 113.

Satcher, D.S.(2000). Executive summary: A report of the surgeon general on mental health. Public Health Report, 115:89-101.

Sherbourne, C. D., \& Stewart, A. L. (1991). The MOS Social Support Survey: Reliability and validity in a patient population. Social Science and Medicine, 32, 705-14.

Venkoba Rao A. (1993).Psychiatry of old age in India. Int Rev Psychiatry.5:165-70.

Vink D., Aartsen M.J., et al.(2008) "Risk factors for anxiety and depression in the elderly: a review.” Journal of Affective Disorders, 106: 29-44.

World Health Organization. (2013) Comprehensive mental health the action plan 2013-2020, Sixty-Sixth World Health Assembly Geneva.

Yesavage J., Brink T., Rose T., Lum O., Huang V., Adey M., Leirer V. (1983). Development and validation of a geriartric depression screening scale: a preliminary report. Journal of Psychiatric Research 17,37-49.

How to cite this article: Singh S (2016), An Empirical Study of Social Support among Depressive and Non-Depressive Elderly People, International Journal of Indian Psychology, Volume 4, Issue 1, No. 82, ISSN:2348-5396 (e), ISSN:2349-3429 (p), DIP:18.01.154/20160401, ISBN:978-1-365-59365-9 